\title{
Effect of Fire on Carrying Capacity of Concrete Columns Confinement with Multi-Layers of CFRP
}

\author{
Eng. Manar Takla ${ }^{1}$ Dr. Ihssan Tarsha ${ }^{2}$ \\ 1.PhD student, Structural Engineering Department Faculty of Engineering, Baath University Homs, Syria \\ 2.Professor, Structural Engineering Department Faculty of Engineering, Baath University Homs, Syria
}

\begin{abstract}
FRP reinforced polymers are widely accepted for use in civil engineering applications to strengthen constructions and application of confinement on the concrete columns, thereby increasing their ductility and increasing their carrying capacity as these materials are characterized by high tensile strength, high strength-to-weight ratio and high corrosion resistance of FRP composites, etc. In addition, the exposure of reinforced concrete structures to fire is one of the most dangers challenges that lead to great destruction and failure the structural in addition to loss of life. With the development of computer simulation theories to study the behavior of elements and structures under the influence of different loads (static, dynamic, thermal, etc.), it is possible to study the behavior of concrete columns under the influence of axial vertical and non-axial structural loads, and compare the results with previous research, thus saving time, effort and cost instead Of laboratory testing. Strengthening concrete columns with fiberreinforced polymers (FRP) has been studied extensively, but the majority of published studies have focused on circular columns. Most concrete columns in the field have square or rectangular cross sections and resist eccentric loading as well. The objective of this study is to investigate the performance of square reinforced concrete (RC) columns, wrapped with carbon FRP subjected to fire so, in this paper, an analytical study was conducted using the ANSYS Workbench program, which follows the finite element method, to determine the effect of layers number of CFRP on carrying capacity of concrete columns and to know the effect of external standard fire on confined concrete columns with CFRP. The numerical results were compared with experimental results as far as possible, and revealed the accuracy of the analytical models, when compared to the experimental studies. The results shown that with increase the layer number of CFRP, the carrying capacity of concrete columns will increase, no benefit with increase the number of CFRP more than 4 layers where polymers materials are sensitive to fire so that it needs to insulation.
\end{abstract}

Keywords: confinement, CFRP, External fire, ANSYS Workbench.

DOI: $10.7176 / \mathrm{CER} / 12-12-01$

Publication date: December $31^{\text {st }} 2020$

\section{Introduction}

Reinforced concrete is the common material used in structural system in the world. The behavior of these structures and their failure modes are extensively studied The use of fiber reinforced polymer (FRP) composites that are externally applied for strengthening reinforced concrete structures such as beams, slabs and columns has been done experimentally by many researchers and has been applied in construction. A column is one of the essential elements in civil engineering structures that transmits loads from the upper levels to the lower levels and then to the soil through the foundations. During their service life, columns un confinement or confined by CFRP can undergo deterioration caused by, overloading, environmental effects, exposing to exterior deteriorating factors like fire, and other factors. Therefore, Failure of columns system in any structure by any reason could lead to a catastrophic failure of the entire building. In addition, the degradation of concrete strength due to short-term exposure to elevated temperature (fire), has attracted attention in the last decades, where The behavior of concrete exposed to fire depends on its mix composition and determined by complex interactions during heating process, and the modes of concrete failure under fire exposure vary according to the nature of fire, loading system, and type of structure.

\section{BACKGROUND}

FRP systems were developed as alternates to steel plate bonding. Bonding steel plates to the tension zones of concrete members with adhesive resins were shown to be viable techniques for increasing their flexural strengths. This technique has been used to strengthen many bridges and high rise buildings around the world. Because steel plates can corrode, leading to a deterioration of the bond between the steel and concrete, and because they are difficult to install, requiring the use of heavy equipment, researchers have looked to FRP materials as an alternative to steel. Experimental work using FRP materials for retrofitting concrete structures was reported as early as 1978 in Germany. Research in Switzerland led to the first applications of externally bonded FRP systems to reinforced concrete bridges for flexural strengthening. FRP systems were first applied to reinforced concrete columns for providing additional confinement in Japan in the 1980s. Previous research and field applications for FRP rehabilitation and strengthening are described in ACI 440.2R-17 (2017) [1]. In Europe, the International Federation 
for Structural Concrete (FIB. 2001) [4] published a bulletin for design guidelines, entitled "externally bonded FRP reinforcement for reinforced concrete structures". In recent years, research into FRP materials as reinforcement for concrete has been steadily increasing, and a number of research gap analyses have been reported which suggest that FRP behavior in fire is a critical research need that must be addressed before these materials will see widespread use in buildings. For example, Karbhari et al. [5] present a durability gap analysis for fiber-reinforced polymer composites in civil infrastructure based on a series of workshops conducted by the Civil Engineering Research Foundation (CERF) and the Market Development Alliance (MDA) in the United States. The gap analysis provides a very instructive overview of the various concerns associated with FRP in fire. Therefore, the study of structural elements confined by carbon fiber and exposed to fire are important topics in the field of civil engineering.

\section{Model Generation}

The ultimate purpose of a finite element analysis is to recreate numerically the behavior of an actual engineering system. In other world, the analysis must use an accurate numerical model of a physical prototype. In the broadest sense, this model consist of the nodes, elements, material properties, real constants, boundary conditions and other features that are used to represent the physical system.

\section{Structural elements $[6,7,12]$}

\subsubsection{Solid65 Element Description}

SOLID65 is used for the 3-D modeling of solids with or without reinforcing bars (rebar). The SOLID65 is capable of cracking in tension and crushing in compression. In concrete applications, for example, the SOLID65 capability of the element may be used to model the concrete while the rebar capability is available for modeling reinforcement behavior. The element is defined by eight nodes having three degrees of freedom at each node: translations in the nodal $\mathrm{x}, \mathrm{y}$, and $\mathrm{z}$ directions. Up to three different rebar specifications may be defined. The concrete element is similar to a 3-D structural solid but with the addition of special cracking and crushing capabilities. The most important aspect of this element is the treatment of nonlinear material properties. The concrete is capable of cracking (in three orthogonal directions), crushing, plastic deformation, and creep. The rebar are capable of tension and compression, but not shear. They are also capable of plastic deformation and creep.

The geometry, node locations, and the coordinate system for this element are shown in Figure 1.

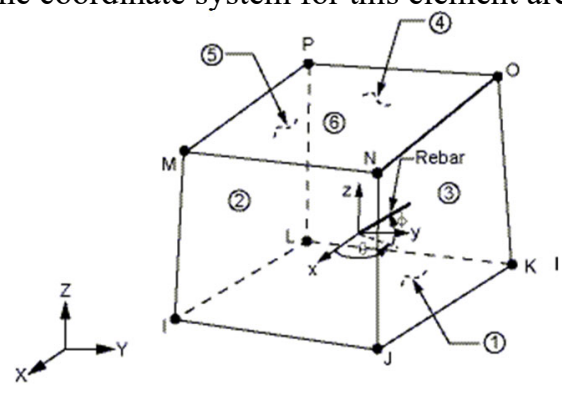

\subsubsection{Link180 Element Description}

Figure 1: SOLID65 Geometry

ANSYS presents element LINK180 to model reinforcing steel, accurately. LINK180 is a spar that can be used in a variety of engineering applications. This element can be used to model trusses, sagging cables, links, springs, etc. This 3-D spar element is a uniaxial tension-compression element with three degrees of freedom at each node: translations in the nodal $\mathrm{x}, \mathrm{y}$, and $\mathrm{z}$ directions. As in a pin-jointed structure, no bending of the element is considered. Plasticity, creep, rotation, large deflection, and large strain capabilities are included. The element is not capable of carrying bending loads. The stress is assumed to be uniform over the entire element. The geometry, node location, and the coordinate system for this element are shown in figure 2.
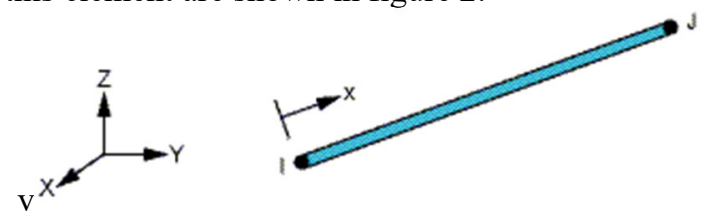

\subsubsection{Solid180 Element Description}

Figure 2: LINK180 Geometry

This element could be used for 3-D modeling of solid structures. It is defined by eight nodes having three degrees of freedom at each node: translations in the nodal $\mathrm{x}, \mathrm{y}$, and $\mathrm{z}$ directions. . The geometry, node location, and the coordinate system for this element are shown in figure 3. 


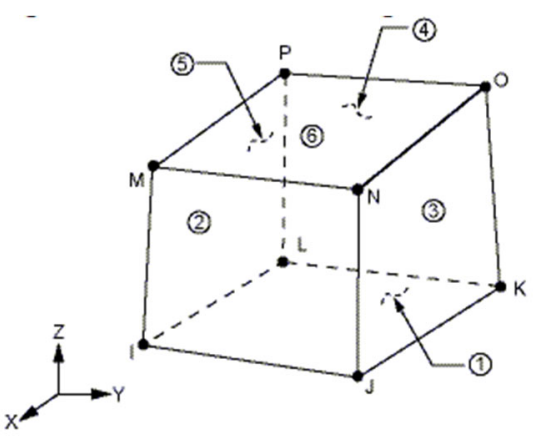

Figure 3: Solid180 Geometry

\section{2 thermal elements}

\subsubsection{Solid 70 Element Description}

This element has a 3-D thermal conduction capability. The element has eight nodes with a single degree of freedom, temperature, at each node. The element is applicable to a 3-D, steady-state or transient thermal analysis. If the model containing the conducting solid element is also to be analyzed structurally, the element should be replaced by an equivalent structural element. This 8-node brick element is used, in this study, to simulate the behavior of concrete at thermal analysis. The geometry, node location, and the coordinate system for this element are shown in figure 4.

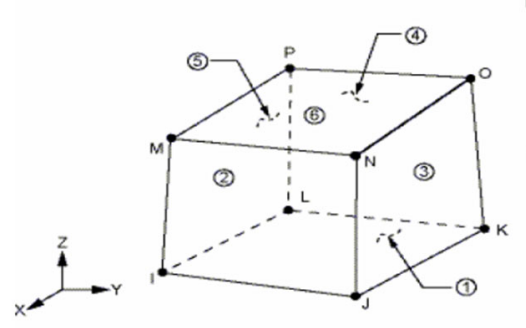

Figure 4: Solid70 Geometry

\subsubsection{Link 33 Element Description}

This element is a uniaxial element with the ability to conduct heat between its nodes. The element has a single degree of freedom, temperature at each node point. The conducting bar is applicable to a steady state or transient thermal analysis. If the model containing the conducting bar element is also to be analyzed structurally, the bar element should be replaced by an equivalent structural element. This element is used in this study, to simulate the behavior of steel reinforcement. The geometry, node location, and the coordinate system for this element are shown in figure 5.

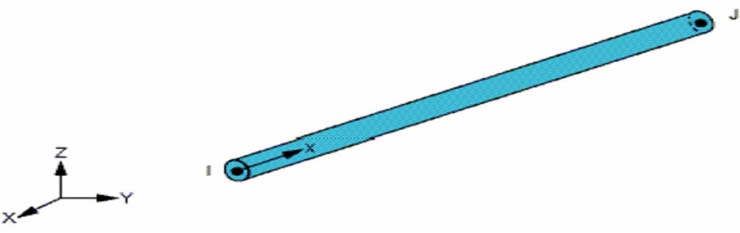

Figure 5: Link33 Geometry

\section{Structural and thermal Analysis}

Experimental model OCO [8] was modeling to define the analysis parameters, and compare between experimental and analytical results. Model properties, material properties and thermal Material properties are shown in table 1, 2,3 respectively. 
Table 1: Model properties

\begin{tabular}{|c|c|}
\hline \multicolumn{2}{|c|}{ Model properties } \\
\hline Cross section $(\mathrm{mm})$ & $(200 \times 200 \times 800)$ \\
\hline Compressive strength of concrete & 79.5 \\
\hline Concrete cover $(\mathrm{mm})$ & 20 \\
\hline Yield strength of longitudinal steel reinforcement $(\mathrm{MPa})$ & 564 \\
\hline Yield strength of transverse steel reinforcement $(\mathrm{MPa})$ & 516 \\
\hline Diameter of longitudinal steel reinforcement $(\mathrm{mm})$ & 12 \\
\hline Diameter of transverse steel reinforcement $(\mathrm{mm})$ & 8 \\
\hline
\end{tabular}

Table2: Material properties

\begin{tabular}{|c|c|c|c|c|}
\hline Material Number & Element Type & \multicolumn{3}{|c|}{ Material properties } \\
\hline \multirow{25}{*}{1} & \multirow{25}{*}{ Solid65 } & \multicolumn{3}{|c|}{ Linear Isotropic } \\
\hline & & Young's Mc & & $47925 \mathrm{MPa}$ \\
\hline & & Poisson's I & & 0,2 \\
\hline & & \multicolumn{3}{|c|}{ Multilinear Isotropic } \\
\hline & & & Strain & Stress(MPa) \\
\hline & & Point1 & 0,000497 & 23,50 \\
\hline & & Point2 & 0,0009 & 37,28 \\
\hline & & Point3 & 0,0014 & 52,93 \\
\hline & & Point4 & 0,0017 & 60,59 \\
\hline & & Point5 & 0,002 & 66,96 \\
\hline & & Point6 & 0,0024 & 73,42 \\
\hline & & Point7 & 0,0026 & 75,78 \\
\hline & & Point8 & 0,0028 & 77,56 \\
\hline & & Point9 & 0,003 & 78,77 \\
\hline & & Point10 & 0,00332 & 79,5 \\
\hline & & \multicolumn{3}{|c|}{ Concrete } \\
\hline & & Open sheal & coef & 0,3 \\
\hline & & Closed shea & r coef & 0,8 \\
\hline & & Uniaxial c & tress & 7.95 \\
\hline & & Uniaxial c & tress & -1 \\
\hline & & Biaxial $\mathrm{Cr}$ & tress & 0 \\
\hline & & Hydrosta & ure & 0 \\
\hline & & Hydro Biax & Stress & 0 \\
\hline & & Hydro Unia & Stress & 0 \\
\hline & & Tensile C & ctor & 0,6 \\
\hline \multirow{12}{*}{2} & \multirow{12}{*}{ Link180 } & \multicolumn{3}{|c|}{ Linear Isotropic(S) } \\
\hline & & \multicolumn{2}{|c|}{ Young's Modulus } & $2,1 \mathrm{e} 5 \mathrm{MPa}$ \\
\hline & & Poisson' & & 0,3 \\
\hline & & \multicolumn{3}{|c|}{ Bilinear Isotropic(S) } \\
\hline & & \multicolumn{2}{|c|}{ Yield stress } & $516 \mathrm{MPa}$ \\
\hline & & Tangent 1 & & $2100 \mathrm{MPa}$ \\
\hline & & \multicolumn{3}{|c|}{ Linear Isotropic(L) } \\
\hline & & \multicolumn{2}{|c|}{ Young's Modulus } & $2,1 \mathrm{e} 5 \mathrm{MPa}$ \\
\hline & & Poisson' & & 0,3 \\
\hline & & \multicolumn{3}{|c|}{ Bilinear Isotropic(L) } \\
\hline & & Yield s & & $564 \mathrm{MPa}$ \\
\hline & & Tangent 1 & & $2100 \mathrm{MPa}$ \\
\hline \multirow{2}{*}{3} & \multirow[t]{2}{*}{ Solid185 } & \multicolumn{3}{|c|}{ Linear Isotropic } \\
\hline & & Young's I & & $2,1 \mathrm{e} 5 \mathrm{MPa}$ \\
\hline
\end{tabular}


Table 3: thermal Material properties

\begin{tabular}{|c|c|c|c|}
\hline \multicolumn{3}{|c|}{ Material properties for element used in thermal analysis } \\
\hline number & element & property & value \\
\hline \multirow{3}{*}{1} & \multirow{3}{*}{ Solid70 } & density $\left[\mathrm{Kg} / \mathrm{m}^{3}\right]$ & $\mathbf{2 3 0 0}$ \\
\cline { 3 - 4 } & & specific heat $[\mathrm{J}] /[\mathrm{Kg}] .[\mathrm{K}]$ & $\mathbf{1 1 0 0}$ \\
\cline { 3 - 4 } & & conductivity $[\mathrm{W}] /[\mathrm{m}] .[\mathrm{K}]$ & $\mathbf{1 . 2}$ \\
\cline { 3 - 4 } & & Thermal expansion & $\mathbf{1 e - 5}$ \\
\hline \multirow{3}{*}{2} & \multirow{3}{*}{ Link33 } & density $\left[\mathrm{Kg} / \mathrm{m}^{3}\right]$ & $\mathbf{7 8 5 0}$ \\
\cline { 3 - 4 } & & specific heat $[\mathrm{J}] /[\mathrm{Kg}] .[\mathrm{K}]$ & $\mathbf{7 0 0}$ \\
\cline { 3 - 4 } & & conductivity $[\mathrm{W}] /[\mathrm{m}] .[\mathrm{K}]$ & $\mathbf{4 5}$ \\
\cline { 3 - 4 } & & Thermal expansion & $\mathbf{1 . 3 e - 5}$ \\
\hline
\end{tabular}

\section{Result of Structural Analysis}

The results of the structural analysis are included in Table 4, and Figures 6, 7, 8, 9, 10, 11 respectively. Figure 12 shows the relationship between the number of carbon fiber layers and the carrying capacity of columns. The Compressive strength of the confined concrete results obtained from the analysis are shown in the table 5. As for Figure 13 shows the relationship between the numbers of carbon fiber layers with compressive strength of confined concrete $\left(f_{\mathrm{CC}}\right)$.

Table 4: the numerical results as obtained by ANSYS Workbench

\begin{tabular}{|c||c||c|}
\hline \multirow{2}{*}{\multicolumn{1}{|c||}{ model }} & \multicolumn{2}{c|}{ Failure load (KN) } \\
\cline { 2 - 3 } & Experimental [8] & Analytical \\
\hline \hline C79.5-L12 & ----- & 3160.7 \\
\hline \hline C79.5-L12-S8 & 3248 & 3218.7 \\
\hline \hline C79.5-L12-S8+1CFRP & 3279 & 3255 \\
\hline C79.5-L12-S8+2CFRP & ---- & 3306.9 \\
\hline \hline C79.5-L12-S8+3CFRP & 3585 & 3468.7 \\
\hline \hline C79.5-L12-S8+4CFRP & ----- & 3479.7 \\
\hline
\end{tabular}

C-Concrete; L-longitudinal reinforcement; $\mathbf{S}$ - stirrups reinforcement

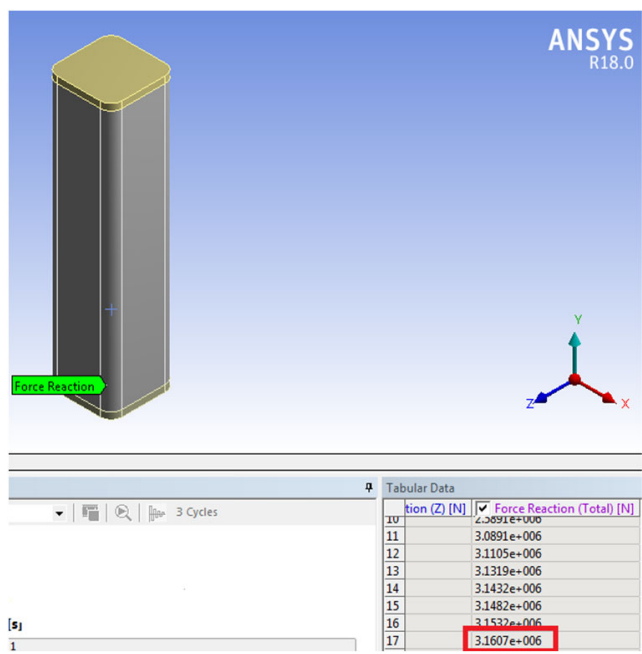

Figure6: failure load of model C79.5-L12
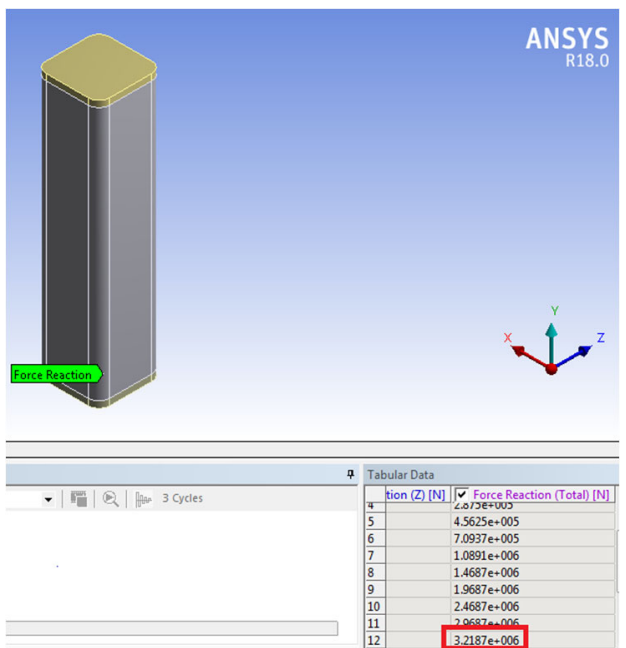

Figure7: failure load of model C79.5-L12-S8 


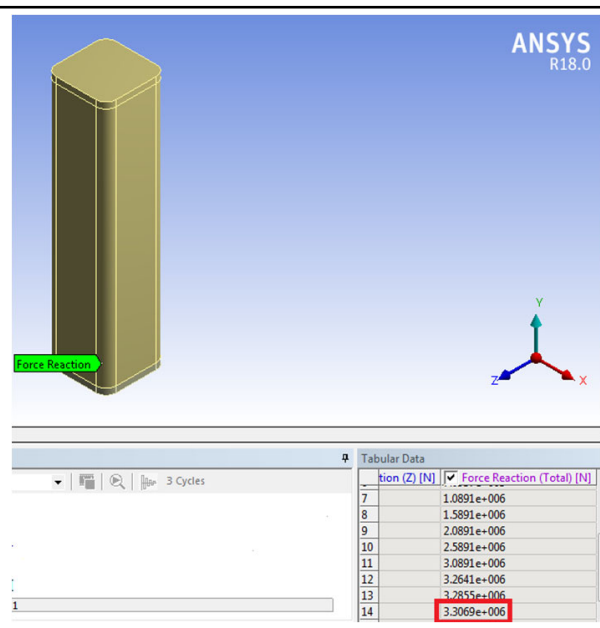

Figure9: failure load of model C79.5-L12-S8+2CFRP


Figure10: failure load of model C79.5-L12-S8+3CFRP

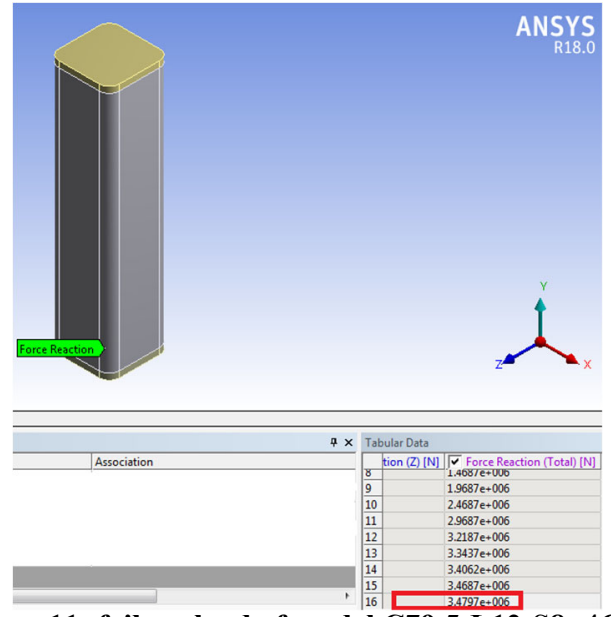

Figure11: failure load of model C79.5-L12-S8+4CFRP

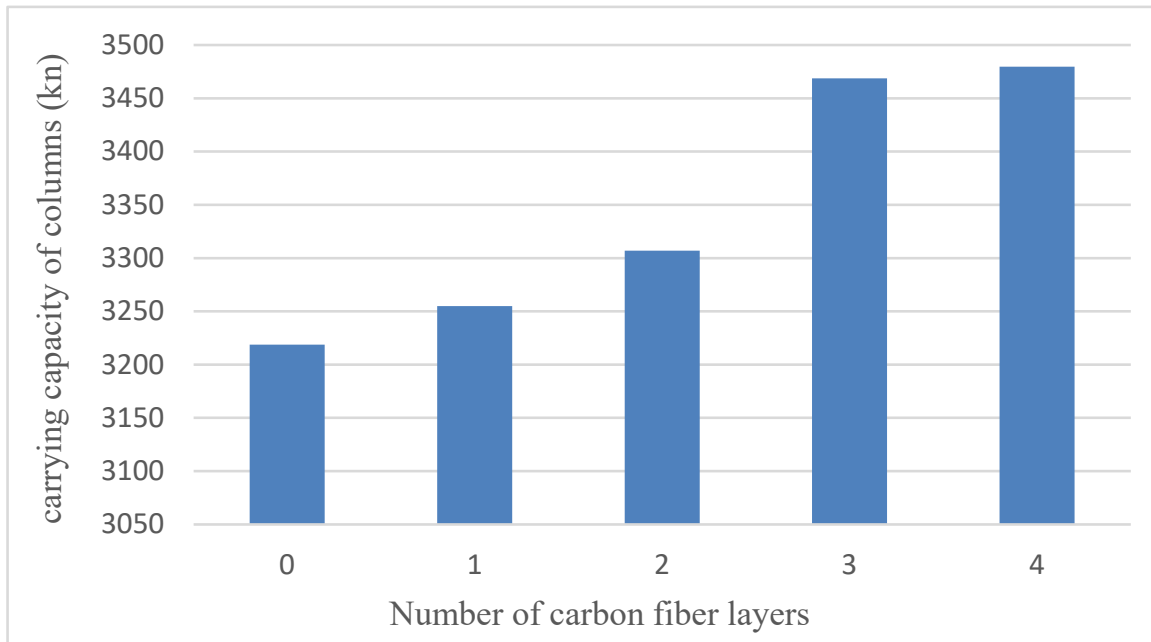

Figure12: The relationship between the number of carbon fiber layers and the carrying capacity of columns 
Table5: Compressive strength of the confined concrete

\begin{tabular}{|c||c|c||}
\hline \multicolumn{2}{|c|}{ the numerical results by ANSYS Workbench } \\
\hline \hline Model & Failure load $(\mathrm{KN})$ & $\begin{array}{c}\text { Compressive strength of the confined } \\
\text { concrete } f_{c c}^{\prime}(M P a)\end{array}$ \\
\hline \hline C79.5-L12-S8 & 3160.7 & $\mathbf{8 2 . 0 6}$ \\
\hline \hline C79.5-L12-S8+1CFRP & 3218.7 & $\mathbf{8 3 . 6 6}$ \\
\hline \hline C79.5-L12-S8+2CFRP & 3255 & $\mathbf{8 5 . 9 5}$ \\
\hline \hline C79.5-L12-S8+3CFRP & 3306.9 & $\mathbf{9 3 . 0 9}$ \\
\hline
\end{tabular}

The Compressive strength of the confined concrete was calculated as follows:

$$
\begin{aligned}
& \mathrm{f}_{\mathrm{cc}}^{\prime}=\frac{\mathrm{N}_{\mathrm{cr}}(\mathrm{C} 79.5-\mathrm{L} 12-\mathrm{S} 8)-\mathrm{N}_{\mathrm{cr}}(\mathrm{C} 79.5-\mathrm{L} 12)}{\mathrm{A}_{\mathrm{cc}}}+f_{\mathrm{c}} \\
& f_{c c}^{\prime}=\frac{N_{c r}(C 79.5-L 12-S 8+n \text { CFRP })-N_{c r}(C 79.5-L 12)}{A_{c c}}+f_{c}^{\prime}
\end{aligned}
$$

Where:

$N_{c r}$ : Failure load (KN).

$\mathrm{f}_{\mathrm{c}}$ : Compressive strength of the concrete.

$\mathrm{f}_{\mathrm{cc}}^{\prime}$ : Compressive strength of the confined concrete.

$\mathrm{A}_{c c}$ : Area of the concrete within the center lines of the perimeter hoop.

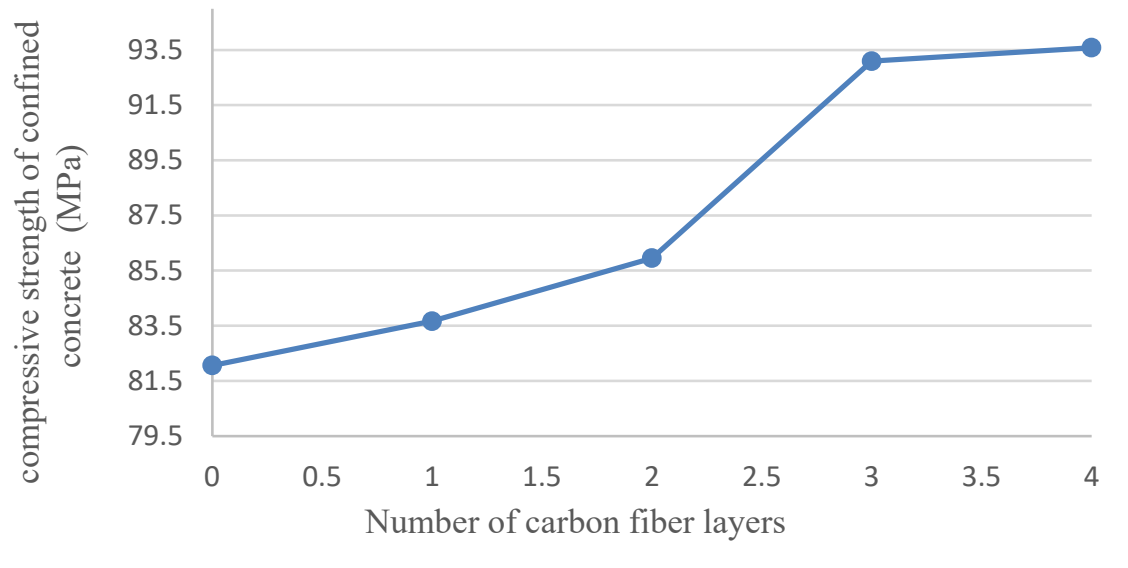

Figure13: The relationship between the number of carbon fiber layers with compressive strength of confined concrete $\left(f_{\mathrm{CC}}\right)$

\section{Thermal-Structure Analysis [9,10,11]}

The analysis consists of two parts: thermal analysis to evaluate the fire temperature distribution inside the columns, and structural analysis to evaluate its structural response, see Figure 14. The analysis was performed by using ANSYS Workbench computer program. The models was exposed to stander fire External Fire from 4 side, the equation of fire is given by: $T_{g}=660 \cdot\left(1-0,687 \cdot e^{-0,32 t}-0,313 \cdot e^{-3,8 t}\right)+20$. Thermal distribution at 60 minute of model C79.5-L12-S8 are shown in Figure 15. As for the table 6 and Figure 16, show the numerical results as obtained by ANSYS Workbench after thermal-structure analysis. 


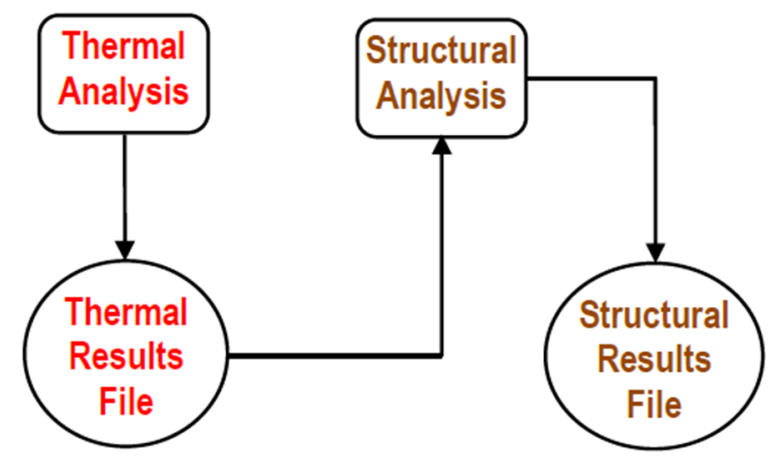

Figure 14: Analysis Methodology

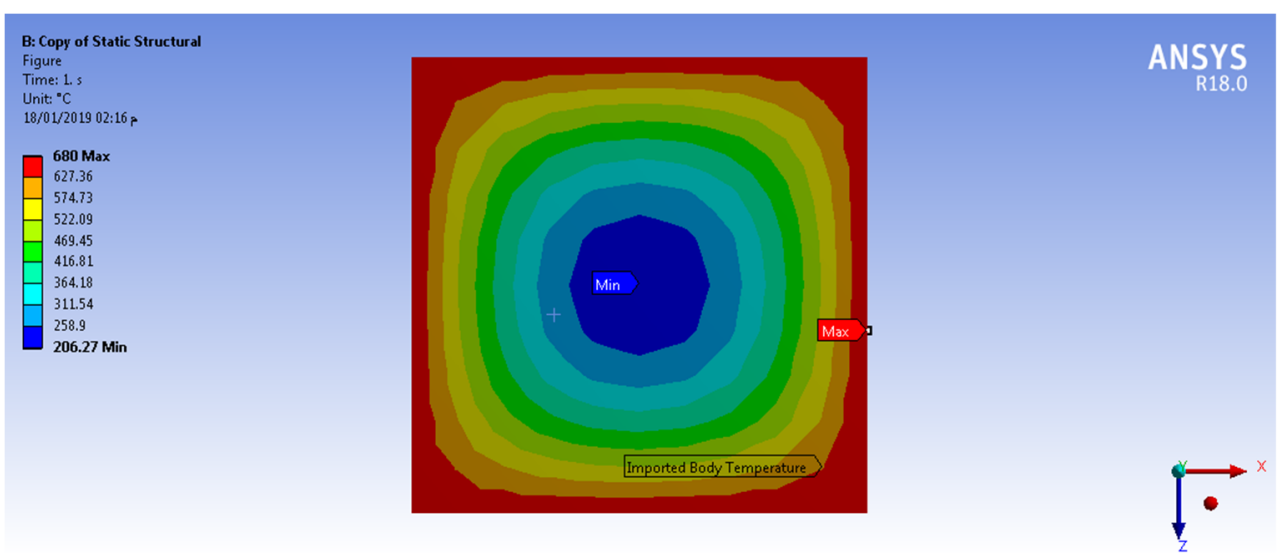

Figure15: Thermal distribution at 60 minute of model C79.5-L12-S8

Table 6: the numerical results as obtained by ANSYS Workbench after thermal-structure analysis

\begin{tabular}{|c||c|}
\hline Model & Analytical Failure load after fire (KN) \\
\hline \hline C79.5-L12 & 2980.4 \\
\hline \hline C79.5-L12-S8 & 2940.2 \\
\hline \hline C79.5-L12-S8+1CFRP & 2910.6 \\
\hline C79.5-L12-S8+2CFRP & 2894.3 \\
\hline \hline C79.5-L12-S8+3CFRP & 2857.6 \\
\hline C79.5-L12-S8+4CFRP & 2827.1 \\
\hline
\end{tabular}

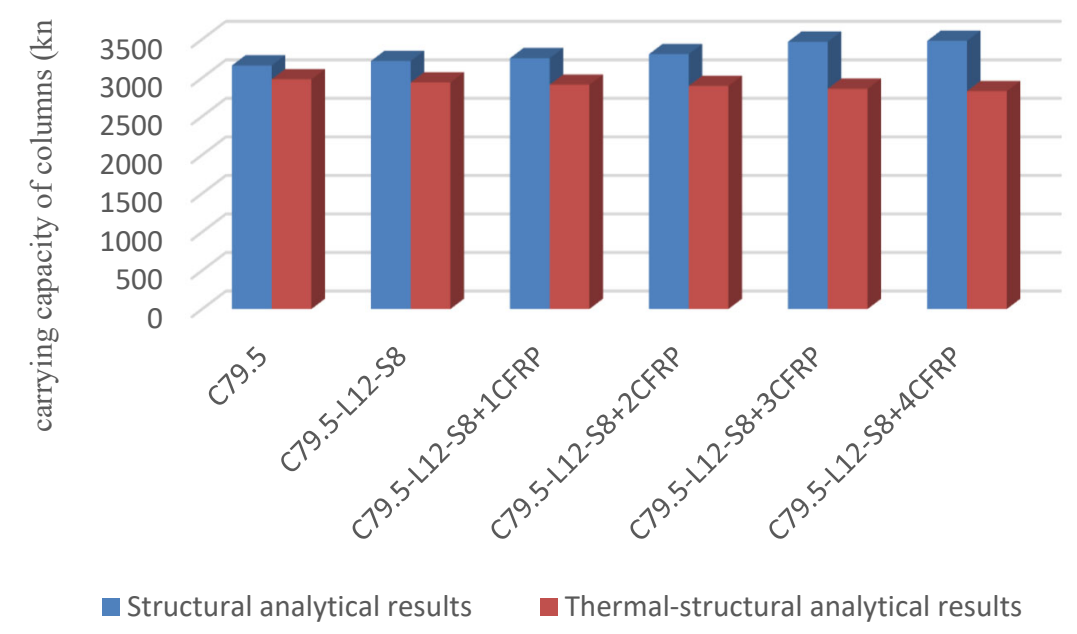

\section{Conclusion}

1. By increasing the number of carbon fiber layers, concrete carrying capacity increases. 
2. There is no great benefit in increasing the number of carbon fiber layers more than 3 layers.

3. Carrying capacity of concrete columns decreased by about $9 \%$ after exposure to fire for 60 minute, while Carrying capacity of concrete columns confined with one layer and four layer of carbon fiber decreased $11-19 \%$ respectively at the same time $(\mathrm{t}=60$ minute $)$.

4. Carbon fiber material is sensitive to heat and requires a heat insulating material.

\section{Recommendations}

1. Conducting experimental studies and comparing the results of this research with the experimental results.

2. Use of carbon fiber insulation materials when exposed to fire and know the effectiveness of these materials.

10. References

[1] ACI 440.2R-17 (2017). Guide for the Design and Construction of Externally Bonded FRP Systems for Strengthening Concrete Structures.

[2] ACI Committee 440. Guide for the Design and Construction of Externally Bonded FRP Systems for Strengthening Concrete Structures; ACI 440.2R-08; American Concrete Institute: Farmington Hills, MI, USA, 2008.

[3] ACI 318M-08 (2008). Building Code Requirements for Structural Concrete and Commentary.

[4] FIB (2001). Externally Bonded FRP Reinforcement for RC Structures. FIB, Lausanne, 138 pp.

[5] Karbhari VM, Chin JW, Hunston D, Benmokrane B, Juska T,Morgan R, Lesko JJ, Sorathia U \& Reynaud D. Durability gap analysis for fiber reinforced composites in civil infrastructure. Journal of Composites for Construction 2003: 7(3): 238-247.

[6] Ihsan Tarsha, Manar Takla, Effect of Fire on Confined Concrete Columns under Axial Loading, IISTE: International Knowledge Sharing Platform, Vol.9, No.9, 2017.

[7] ANSYS. Manuals, 2015.

[8] M. W. Hadi, "Axial and flexural performance of square RC columns wrapped with CFRP under eccentric loading," Journal of Composites for Construction , vol. 16, no. 6, pp. 640-649, 2012.

[9] Ihssan Tarsha, Manar Takla, Ultimate load for composite column Subjected to ISO 834 fire, Journal of AlBaath University, Vol.38, 2016.

[10] Manar Takla, Behavior of Concrete Columns subjected to ASTM-E119 fire, Journal of Al- Baath University, Vol.39,No, 2017.

[11] Ihssan Tarsha, The Effect Of Fire Modeling on heat Distributions In Composite columns, Journal of Al Baath University, VO.32, 2010.

[12] SAS (2008). ANSYS 12 ,"Finite Element Analysis System", SAS IP, Inc, USA. 